\title{
Demonstration of aluminium in iliac bone: correlation between aluminon and solochrome azurine staining techniques with data on flameless absorption spectrophotometry
}

\author{
H A ELLIS,* M M C PANG, $†$ W H B MAWHINNEY,* A W SKILLEN† \\ From the Departments of ${ }^{*}$ Pathology and $†$ Clinical Biochemistry, Royal Victoria Infirmary, Newcastle upon \\ Tyne
}

SUMMARY The presence of excess aluminium was investigated in 204 samples of iliac bone from 197 patients with chronic renal failure by using the aluminon and solochrome azurine staining techniques. The results were compared with values obtained by atomic absorption spectrophotometry (AAS). Overall, the staining reactions correlated with the AAS data, but the solochrome azurine stain was positive more often than was the aluminon stain (in $90.6 \%$ and $62.3 \%$, respectively, of bone samples with greater than the control group mean $+3 \mathrm{SD}$ (that is, in the range 17.8 to $113.4 \mu \mathrm{g}$ aluminium/g bone). Solochrome azurine staining was consistently positive in all cases, with $>23.1 \mu \mathrm{g}$ aluminium/g bone but the corresponding aluminon stain was occasionally inexplicably negative in this range. In some samples solochrome azurine was positive in parts of old unresorbed cement lines when the aluminon stain was negative and the bone aluminium concentration was within the normal range or slightly increased.

The stains, particularly solochrome azurine, have the advantage over AAS in that they indicate the location as well as the presence of excess bone aluminium.

Bone disease caused by aluminium deposits is a well recognised complication of renal failure in patients treated by dialysis or with oral aluminium hydroxide. ${ }^{1-3}$ Aluminon is often used to show or quantify aluminium in sections of undecalcified bone. ${ }^{49}$ Clark and Krueger emphasised that aluminon is not a specific reagent for aluminium and concluded that its histochemical application requires verification by quantitative techniques. ${ }^{10}$ In our experience positive aluminon staining is easily recognisable when the bone aluminium content (measured by neutron activation analysis) is high, ${ }^{5}$ as in patients with osteomalacia induced by aluminium and in animals injected with aluminium chloride. ${ }^{3}$ With lesser amounts of aluminium in bone, interpretation may be difficult. More recently solochrome azurine staining has been advocated to show aluminium in sections of undecalcified bone." We routinely use both the solochrome azurine and aluminon techniques and have found solochrome azurine much easier to interpret. To further investigate their sensitivity and specificity we

Accepted for publication 19 May 1988 undertook a comparative study of the two staining methods and correlated the results obtained with values for bone aluminium determined by flameless atomic absorption spectrophotometry (AAS). As aluminon and solochrome azurine may react with iron $^{10}$ "1 all bone samples were stained also with Perls's stain.

\section{Material and methods}

Transiliac bone biopsy specimens ( $7 \mathrm{~mm}$ diameter) and necropsy samples were fixed in Analar grade absolute ethanol. One longitudinal half was embedded in plastic for the preparation of undecalcified sections ${ }^{12}$ and the other half used for aluminium analysis. Two hundred and four (198 from biopsy, six from necropsy) suitable specimens were available from 197 patients with chronic renal failure, there being two biopsy specimens from each of six patients and both biopsy and necropsy specimens in another. Iliac bone was also obtained at necropsy from 27 control subjects who had died suddenly as a result of trauma or from causes other than renal disease. Undecalcified sections 
were stained by aluminon (at $56^{\circ} \mathrm{C}, \mathrm{pH} 5.2$ ) using a slight modification of the method described by Buchanan, Ihle, and Dunn ${ }^{4}$ and by acid solochrome azurine according to the method of Denton, Freemont, and Ball. " The presence and location of the staining reactions were assessed (HAE, WHBM) without prior knowledge of the results of the aluminium analyses. The presence of iron was shown by Perls's stain.

Bone samples were dried in stainless steel crucibles at $180^{\circ} \mathrm{C}$ until of constant weight, then crushed, and a weighed aliquot $(30 \mathrm{mg})$ ashed in a muffle furnace $\left(500-600^{\circ} \mathrm{C}\right)$ for 18 hours. The ashed sample was dissolved in nitric acid and aluminium was determined using a Perkin-Elmer 603 spectrophotometer (HGA76B Electrothermal Furnace). ${ }^{13}$ Final results were expressed as $\mu \mathrm{g}$ elemental aluminium/g dried bone.

Assessment of intrabatch imprecision of bone aluminium measurements showed a coefficient of variation $(\mathrm{CV})$ of $8.2 \%(n=10)$ for samples containing $85 \mu \mathrm{g}$ aluminium/g dry weight of bone and a CV of $10.5 \%(n=10)$ for samples containing $7.4 \mu \mathrm{g}$ aluminium/g dry weight. Interbatch imprecision was determined by repeatedly measuring the aluminium content of three samples of bone over six to 11 days. For bone samples containing $6 \cdot 7,32 \cdot 8$, and $88.9 \mu \mathrm{g} /$ aluminium/ $\mathrm{g}$ dry weight of bone the interbatch coefficients of variation were, $12 \cdot 1 \%(n=6), 5 \cdot 0 \%(n=5)$, and $5 \cdot 1 \%(n=4)$, respectively.

\section{Results}

\section{BONE ALUMINIUM (table 1)}

Apart from the control values many of the data were not normally distributed and statistical comparisons between the various groups studied were made using the Mann-Whitney U test. The values for the bone samples from renal patients were significantly greater than those for the controls $(p<0.001)$. This was attributable largely to the samples from patients receiving some form of renal replacement therapy. Thus for predialysis patients the bone aluminium did

Table 1 Bone aluminium content in iliac bone from 27 control subjects and 204 samples from 197 patients with renal diseases

\begin{tabular}{lrrrr}
\hline & & \multicolumn{3}{c}{ Bone aluminium $(\mu g / g$ dry wt) } \\
\cline { 4 - 6 } Group & $(n=)$ & Mean & Median & Range \\
\hline Controls & 27 & 7.6 & 7.8 & $1.5-13.3$ \\
All renal samples & 204 & 15.1 & 9.2 & $1.5-113.4$ \\
Predialysis & 97 & 8.0 & 6.9 & $1.5-32.9$ \\
Renal replacement therapy & 107 & $* 21.6$ & 16.3 & $1.9-113.4$ \\
\hline
\end{tabular}

Control mean (SD) 7.6 (3.4)/ $\mu \mathrm{g} / \mathrm{g}(\mathrm{n}=27)$.

* Significantly increased compared with samples from controls and predialysis group $(p<0.001)$.
Table 2 Relation between staining reactions and bone aluminium content in 204 samples of iliac bone

\begin{tabular}{|c|c|c|c|c|}
\hline \multirow[b]{2}{*}{ Stain } & \multirow{2}{*}{$\begin{array}{l}\text { No (\%) } \\
\text { of samples }\end{array}$} & \multicolumn{3}{|c|}{ Bone aluminium ( $\mu \mathrm{g} / \mathrm{g}$} \\
\hline & & Mean & Median & Range \\
\hline $\begin{array}{l}\text { Negative } \\
\text { Aluminon positive }\end{array}$ & $\begin{array}{r}129(63 \cdot 2) \\
41(20 \cdot 1)\end{array}$ & $\begin{array}{r}7.5 \\
* 22.2\end{array}$ & $\begin{array}{l}36 \cdot 8 \\
28 \cdot 8\end{array}$ & $\begin{array}{l}1 \cdot 5-22 \cdot 5 \\
6 \cdot 0-113 \cdot 4\end{array}$ \\
\hline positive & $75(36 \cdot 8)$ & $* 19.5$ & $23 \cdot 5$ & $6 \cdot 0-113 \cdot 4$ \\
\hline
\end{tabular}

*Significantly increased $(p<0.001)$ compared with control and with negative samples.

not differ $(p>0 \cdot 10)$ from that for the control group but was significantly less than that for the group receiving renal replacement therapy $(p<0.001)$.

\section{STAINING}

The results are summarised in table 2 . A positive staining reaction for aluminium was obtained more often with solochrome azurine.

There was a good correlation between both the aluminon and solochrome azurine stains and the bone aluminium content as determined by AAS, but individual exceptions were noted (tables $2-4$ ). In bone samples giving a negative reaction with both staining techniques the bone aluminium content did not differ from that for the control $(p>0 \cdot 10)$. Positive aluminon and solochrome azurine stains were both associated with significantly increased amounts of bone aluminium $(\mathrm{p}<0.001)$ (table 2$)$ and there was no significant difference in the values for the aluminium content of samples which gave a positive reaction with the two stains $(p>0 \cdot 10)$. The solochrome azurine stain, however, was more often positive and more easily recognised in many samples, particularly when the aluminium was located solely in parts of old cement lines. Table 3 indicates the percentage positive reactions for each stain in relation to increasing bone aluminium content (expressed at intervals based on the control group mean and standard deviation). In only eight cases was there osteomalacia caused by aluminium deposits (table 4).

\section{“DISCREPANCIES" BETWEEN BONE ALUMINIUM} AND STAINING REACTIONS

(i) In five of 53 samples with aluminium deposits within the range 17.8-113.4 $\mu \mathrm{g} / \mathrm{g}$ (that is, greater than control mean + 3SD) both the aluminon and solochrome azurine stains were interpreted as being negative. Assuming that the AAS values, which varied from 18.3 to $22.5 \mu \mathrm{g} / \mathrm{g}$, are correct then there was a $9.4 \%$ incidence of "false" negative staining in this range.

(ii) In 27 of 151 samples with values less than the control mean +3 SD either the aluminon (10 samples) 
Table 3 Percentage positive aluminon and solochrome azurine stains related to bone aluminium content

\begin{tabular}{|c|c|c|c|c|c|}
\hline Positive stain & Bone alum & $g(g)$ & & & \\
\hline $\begin{array}{l}\text { Aluminon } \\
\text { Solochrome azurine }\end{array}$ & $\begin{array}{l}<\bar{x}_{c} \\
(n=80) \\
1(1 \cdot 3 \%) \\
2(2 \cdot 5 \%)\end{array}$ & $\begin{array}{l}\bar{x}_{c}+1 \text { SD } \\
(n=39) \\
2(5 \cdot 1 \%) \\
7(17.9 \%)\end{array}$ & $\begin{array}{l}\overline{\mathrm{x}}_{\mathrm{c}}+2 \mathrm{SD} \\
(\mathrm{n}=18) \\
2(11 \cdot 1 \%) \\
8(44 \cdot 4 \%)\end{array}$ & $\begin{array}{c}\bar{x}_{c}+3 \text { SD } \\
(n=14) \\
5(35 \cdot 7 \%) \\
10(71 \cdot 4 \%)\end{array}$ & $\begin{array}{l}\bar{x}_{c}+>3 \mathrm{SD} \\
(\mathrm{n}=53) \\
33(62 \cdot 3 \%) \\
48(90 \cdot 6 \%)\end{array}$ \\
\hline
\end{tabular}

$\overline{\mathbf{x}}_{c}$, control group mean $7 \cdot 6$, SD $3 \cdot 4$

Table 4 Aluminium stain reactions and bone aluminium content in 29 patients with osetomalacia

\begin{tabular}{|c|c|c|c|c|c|}
\hline & \multicolumn{3}{|c|}{ Predialysis $(n=14)$} & \multicolumn{2}{|c|}{$\begin{array}{l}\text { Renal replacement } \\
\text { therapy }(n=15)\end{array}$} \\
\hline $\begin{array}{l}\text { Aluminium stain } \\
\text { Bone aluminium } \\
(\mu \mathrm{g} / \mathrm{g})\end{array}$ & $\begin{array}{l}(1)^{*} \\
\text { positive } \\
32 \cdot 9\end{array}$ & $\begin{array}{l}\text { Mean } \\
\text { Median } \\
\text { Range }\end{array}$ & $\begin{array}{l}(13) \\
\text { negative } \\
6.5 \\
7.0 \\
1.5-14.0\end{array}$ & $\begin{array}{l}(7) \dagger \\
\text { positive } \\
40 \cdot 1 \ddagger \\
29 \cdot 1 \\
13 \cdot 5-113 \cdot 4\end{array}$ & $\begin{array}{l}\text { (8) } \\
\text { negative } \\
7 \cdot 5 \\
5 \cdot 3 \\
1 \cdot 9-22.5\end{array}$ \\
\hline
\end{tabular}

* Solochrome azurine positive; tsolochrome azurine positive in seven, aluminon positive in six.

tSignificantly increased $(p<0.001)$ osteomalacia induced by aluminium in one predialysis and seven $\dagger$ dialysis patients.

or solochrome azurine (27 samples) stains were positive. Although in 14 of the 27 samples the aluminium content was greater than the upper limit of the control group $(13.3 \mu \mathrm{g} / \mathrm{g})$, in the remaining 13 , aluminium values were within the normal range. The aluminon stain was positive in only three samples-in cement lines in two and additionally in the mineralisation front in the third. The solochrome azurine stain was positive in all 13 samples - in old cement lines in 10 and in both cement lines and mineralisation fronts in three. A total of 129 samples had aluminium values within the reference range, giving "false" positive staining rates of $2.3 \%$ and $10.1 \%$, respectively, for aluminon and solochrome azurine staining reactions. The corresponding "false" positive rates were $1.5 \%$ and $6.4 \%$ for the 204 samples.

Variable amounts of stainable iron pigment were present within marrow macrophages in $150(73.5 \%)$ bone samples and in the tissue lining trabecular bone surfaces in $85(41.7 \%)$. The presence of iron did not seem to affect the staining reactions for aluminium in bone. The positive Perls's reaction was almost invariably located at the bone surface (endosteum); the stains for aluminium were positive at the interface between osteoid and mineralised bone and in cement lines. There was only one sample in which some cement lines stained positively with both aluminon and solochrome azurine and by the Perls's technique.

\section{Discussion}

Earlier studies reported from this hospital were concerned with patients on haemodialysis with osteomalacia induced by aluminium. ${ }^{3}$ The bones were shown to contain great excesses of aluminium by neutron activation analysis. The present study was deliberately restricted to samples in which relatively small increases of bone aluminium were expected as we were especially interested in determining the sensitivity of the aluminon and solochrome azurine stains and osteomalacia was present in only one predialysis and seven dialysis patients (table 4). Varying degrees of intensity of staining were noted with generally more intense staining in the bones, which were subsequently shown by AAS to have the higher concentrations of aluminium. The intensity of the staining reaction, for example with aluminon, is not strictly linearly related to the concentration of aluminium ${ }^{10}$ and for the present we were concerned only to determine whether the individual stain was positive and its location. The study shows clearly that aluminon gives a positive reaction less often than does solochrome azurine in samples shown by AAS to have an increased aluminium content. This is especially the case with lesser amounts of aluminium in the bone within the range studied. We agree with Denton et $a l^{1}$ that solochrome azurine staining indicates a more extensive distribution of aluminium in both compact and cancellous bone than is often apparent with aluminon.

With regard to sensitivity, there was no precise cut off point at one aluminium concentration with either the aluminon or solochrome azurine stains. All of our samples with bone aluminium of more than $23.1 \mu \mathrm{g} / \mathrm{g}$ gave a positive stain with solochrome azurine. In those positive samples with less than $23 \cdot 1 \mu \mathrm{g} / \mathrm{g}$ aluminium the stain was generally less intense or confined to parts of old cement lines. Small localised deposits of aluminium shown by solochrome azurine would not be expected to give rise to an overall increase in bone aluminium content, and the "false" positive rate for the solochrome azurine staining reaction $(10 \cdot 1 \%)$ is probably unduly high. Our cut off point seems to be similar to that reported by Denton et $a l^{11}$ who noted positive solochrome azurine staining when bone aluminium was in the range 16 to 406 , mean $141 \mu \mathrm{g} / \mathrm{g}$. Fifty three (86.9\%) of our samples with bone aluminium of more than $16 \mu \mathrm{g} / \mathrm{g}$ had positive solochrome azurine stains.

Results with the aluminon stain tended to be capricious. Sometimes increased amounts of alumin- 
ium by AAS were clearly visible with solochrome azurine whereas the aluminon stain was repeatedly negative. Sporadic negative aluminon stains were noted in individual cases, with up to $63.9 \mu \mathrm{g}$ aluminium $/ \mathrm{g}$ bone. Aluminon often failed to show aluminium in parts of old cement lines clearly defined by solochrome azurine. In the higher range of aluminium concentrations (more than $16 \mu \mathrm{g} / \mathrm{g}$ ) the aluminon stain was positive in $35(57.4 \%)$ samples. There is no clear explanation for the discrepancy between solochrome azurine and aluminon staining, or for the occasional failure of both stains in bone with increased aluminum content. There is no obvious reason to suspect the spectrophotometric data. The possibility that the occasional specimen was contaminated during the preparations for AAS analysis cannot be completely excluded but seems unlikely as all specimens were handled in the same manner. Furthermore, others have noted the phenomenon of a negative aluminon stain when bone aluminium has been shown by AAS to be increased. ${ }^{14}{ }^{15}$ Possibly, some unrecognised substance interferes in the aluminon complex formed with aluminium.

The aluminon and solochrome azurine stains are not entirely specific for aluminium and may react with-for example, iron and beryllium. ${ }^{11} 11$ In particular, iron, which is often present in excess amounts in the marrow macrophages of patients with renal disease, is relevant here. The darker brownish-red colour obtained with aluminon and iron, however, is readily distinguishable from the bright cherry-red associated with aluminium. Difficulty arises when both iron and aluminium are presumed to be colocated when the colour with aluminon is brownishred and the Perls's stain is positive. In such cases any doubt could be resolved by spectrophotometric analysis, or preferably, by microprobe studies. ${ }^{116}$ Although, like others we have seen bone biopsy specimens from several patients with dialysis osteomalacia in which iron was present at the interface between osteoid and mineralised bone and where the aluminon staining gave rise to a reddish-brown colour, ${ }^{17}$ in the present study the presence of iron did not interfere with interpretation of the staining reactions. The location of iron in bone was generally different from that of aluminium and in none of the present cases was there a positive Perls's reaction in the region of the mineralisation front. In only one sample was there a positive reaction for haemosiderin in cement lines which also stained in consecutive sections by both aluminon and solochrome azurine. The bone aluminium content of this sample was $9.8 \mu \mathrm{g} / \mathrm{g}$, and in the absence of electron or laser microprobe analysis data we are uncertain whether the positive stains for aluminium were spurious due to reaction with iron alone or if both iron and aluminium were located in the same place at the same time.
We conclude that the aluminon and solochrome azurine staining techniques are suffiiciently "specific" and sensitive to be of clinical value in showing the presence of excess aluminium in undecalcified sections of bone biopsy specimens. Solochrome azurine is positive more often and indicates more widespread deposition of aluminium than is suggested by the aluminon stain. A positive reaction, in addition to showing or confirming the cause of any osteomalacia, may be the first indication that the patient is at possible risk from the effects of aluminium intoxication. Demonstration of stainable bone aluminium has certain advantages over serum aluminium data alone. ${ }^{18}$ After exposure to aluminium the excess bone aluminium may persist for prolonged periods and still be present when the serum aluminium concentration has diminished. The staining techniques have the advantage over bone spectrophotometry in that they indicate the location of the excess bone aluminium, and the presence of aluminium in the region of the mineralisation fronts is of greater importance for mineralisation than are deposits deep in mineralised bone cement lines.

We thank Mrs SM Channon, department of clinical biochemistry, for help with the atomic absorption spectrophotometry and Miss Elizabeth Wark for typing the manuscript.

\section{References}

1 Ward MK, Feest TG, Ellis HA, et al. Osteomalacic dialysis osteodystrophy: evidence for a water-borne aetiological agent, probably aluminium. Lancet 1978;i:841-5.

2 Pierides AM, Edwards WE, Cullum UX, McCall JT, Ellis HA. Hemodialysis encephalopathy with osteomalacic fractures and muscle weakness. Kidney Int 1980;18:115-24.

3 Ellis HA. Aluminium induced osteomalacia in patients with chronic renal failure and in animals. Nieren-und Hochdruckkrankheiten 1983;12:S198-S206.

4 Buchanan MRC, Ihle BU, Dunn CM. Haemodialysis related osteomalacia: a staining method to demonstrate aluminium. $J$ Clin Pathol 1981;34:1352-4.

5 Ellis HA, Mawhinney WHB. Aluminium-induced dialysis osteomalacia. J Clin Pathol 1982;35:792-3.

6 Maloney NA, Ott SM, Alfrey AC, Miller NL, Coburn JW, Sherrard DJ. Histological quantitation of aluminum in iliac bone from patients with renal failure. J Lab Clin Med 1982; 99:206-16.

7 Smith PS, McClure J. Localisation of aluminium by histochemical and electron probe $x$-ray microanalytical techniques in bone tissue of cases of renal osteodystrophy. J Clin Pathol 1983;35:1283-93.

8 McClure J, Fazzalari NL, Fassett RG, Pugsley DJ. Bone histoquantitative findings and histochemical staining reactions for aluminium in chronic renal failure patients treated with haemodialysis fluids containing high and low concentrations of aluminium. J Clin Pathol 1983;36:1281-7.

9 McClure J, Fazzalari NL, Fassett RG, Pugsley PG. Changes in bone histoquantitative parameters and histochemical staining reactions for aluminium in a group of patients with chronic renal failure following a reduction in the aluminium concentration of the haemodialysis fluid. J Clin Pathol 1984;37:743-7. 
10 Clark RA, Krueger GL. Aluminon: its limited application as a reagent for the detection of aluminum species. $J$ Histochem Cytochem 1985;33:729-32.

11 Denton J, Freemont AJ, Ball J. Detection and distribution of aluminium in bone. J Clin Pathol 1985;37:136-42.

12 Mawhinney WHB, Ellis HA. A technique for plastic embedding of mineralised bone. J Clin Pathol 1983;36:1197-9.

13 Channon SM, Mawhinney WHB, Rodger RSC, et al. Accumulating aluminium deposition in bone due to aluminium hydroxide ingestion in patients with renal failure. In: Taylor A, ed. Aluminium and other trace elements in renal disease. London: WB Saunders, 1986:118-22.

14 Ott SM, Maloney NA, Coburn JW, Alfrey AC, Sherrard DJ. The prevalence of bone aluminum deposition in renal osteodystrophy and its relation to the response to calcitriol therapy. $N$ Engl J Med 1982;307:709-13.
15 Ihle B, Buchanan M, Stevens B, et al. Aluminum associated bone disease: clinico-pathologic correlation. Am J Kidney Dis 1982; 2:255-63.

16 Verbueken AH, Van de Vyver L, Visser WJ, Van Grieken RE, De Broe ME. Laser microprobe mass analysis (LAMMA) to verify the aluminon staining of bone. Stain Technol 1986;61:287-94.

17 Pierides AM, Myli MB. Iron and aluminum osteomalacia in hemodialysis patients. N Engl J Med 1984;310:323.

18 Cundy T, Kanis JA. Serum aluminium measurements in renal bone disease. Lancet 1983;i:1168.

Requests for reprints to: Mr W A B Mawhinney, Department of Pathology, Royal Victoria Infirmary, Newcastle upon Tyne NE1 4LP, England. 